\title{
Application of Engineered Zinc Finger Proteins Immobilized on Paramagnetic Beads for Multiplexed Detection of Pathogenic DNA
}

\author{
Jiyoung Shim ${ }^{1}$, Langley Williams ${ }^{1}$, Dohyun Kim², Kisung Ko ${ }^{3}$, and Moon-Soo Kim ${ }^{1 *}$ \\ 'Department of Chemistry, Western Kentucky University, Bowling Green, KY 42101, USA \\ ${ }^{2}$ Department of Mechanical Engineering, Myongji University, Yongin 17058, Republic of Korea \\ ${ }^{3}$ Department of Medicine, College of Medicine, Chung-Ang University, Seoul 06974, Republic of Korea
}

\begin{abstract}
Micro-scale magnetic beads are widely used for isolation of proteins, DNA, and cells, leading to the development of in vitro diagnostics. Efficient isolation of target biomolecules is one of the keys to developing a simple and rapid point-of-care diagnostic. A zinc finger protein (ZFP) is a doublestranded (ds) DNA-binding domain, providing a useful scaffold for direct reading of the sequence information. Here, we utilized two engineered ZFPs (Stx2-268 and SEB-435) to detect the Shiga toxin (stx2) gene and the staphylococcal enterotoxin B (seb) gene present in foodborne pathogens, Escherichia coli 0157 and Staphylococcus aureus, respectively. Engineered ZFPs are immobilized on a paramagnetic bead as a detection platform to efficiently isolate the target dsDNA-ZFP bound complex. The small paramagnetic beads provide a high surface area to volume ratio, allowing more ZFPs to be immobilized on the beads, which leads to increased target DNA detection. The fluorescence signal was measured upon ZFP binding to fluorophore-labeled target dsDNA. In this study, our system provided a detection limit of $\leq 60 \mathrm{fmol}$ and demonstrated high specificity with multiplexing capability, suggesting a potential for development into a simple and reliable diagnostic for detecting multiple pathogens without target amplification.
\end{abstract}

Keywords: Multiplexed double-stranded DNA detection, zinc finger proteins, magnetic beads, foodborne pathogen

Received: June 20, 2021 Accepted: July 7, 2021

First published online: July 9, 2021

*Corresponding author Phone: +1-270-745-4362 Fax: +1-270-745-5361 E-mail:moon-soo.kim@wku.edu

pISSN 1017-7825 eISSN 1738-8872

Copyright(C) 2021 by The Korean Society for Microbiology and Biotechnology

\section{Introduction}

Facile and rapid analytical technology has been developed for diverse applications such as clinical diagnostics [1] , food analysis, and environmental monitoring over the past two decades [2]. The development of simple and robust technology for pathogen detection is still in great demand to manage outbreaks and reduce health risks associated with specific pathogen infection. The conventional identification method for detection of pathogens is time-consuming culture of bacteria [3-5]. Thus, molecular diagnostic technology is desirable for its rapid detection. In particular, polymerase chain reaction (PCR) technology has been established as a quick and sensitive technique [6]. Additionally, the combination of PCR with a DNA microarray has been studied for the multiplexed detection of pathogens and biomarkers [7-11]. However, DNA hybridization is costly and time-consuming, requiring complicated double-stranded (ds) DNA denaturation and subsequent renaturation with carefully designed primers or probes $[7,12,13]$.

The most common Cys2-His2 zinc finger domain is a useful scaffold for the construction of customized DNAbinding proteins that can read the sequence information directly from dsDNA [14, 15]. Each zinc finger protein (ZFP) forms a $\beta \beta \alpha$ structure, in which two cysteine and histidine residues coordinate a zinc ion. Amino acid residues at positions $-1,3$, and 6 on the a-helix recognition module interact with specific DNA bases [16]. Twentyfive of the thirty amino acids in the repeat fold around a zinc ion to form a finger and the remaining five amino acids (TGEK(R)P) supply a short consensus linker between consecutive fingers [17]. Each ZF domain recognizes three to four nucleotides of DNA [18-21] and ZF domains can be linked to form multi-finger proteins using a modular assembly approach [22]. This modular assembly approach enables the rapid construction of multi-finger domains for binding any desired DNA sequence with high specificity [22]. Previously, we have demonstrated direct detection of specific dsDNA using engineered ZFPs by employing SEER-LAC (Sequence-Enabled Reassembly of TEM $1 \beta$-lactamase) system [23,24] in a colorimetric method, and chemiluminescent assay [25]. Other studies have been conducted utilizing ZFPs to detect miRNA-21 [26] and DNA methylation [27]. 
Magnetic beads can be functionalized with target moieties for efficient separation and detection of target molecules in a fast and simple procedure [28]. Micro-scale magnetic beads can be easily detected using fluorescence microscopy, which is useful for quick and specific detection of various biomolecules such as cancer biomarkers and cells $[1,29]$. Shim et al. [30] conjugated antibodies to magnetic nanoparticles for rapid and facile detection of Salmonella Typhimurium. Hayes et al. [31] demonstrated a fast interaction time when using magnetic particles for a heterogeneous immunoassay. Owing to a larger surface to volume ratio, this study utilized magnetic beads for immobilizing the engineered ZFPs, thus enabling more target DNA binding. Here, we have developed a rapid, direct, and multiplexed dsDNA detection method by magnetically isolating the bead-bound complex of immobilized ZFPs (Stx2-268 and SEB-435) and fluorophore-labeled pathogenic dsDNA. Foodborne pathogens, E. coli $\mathrm{O} 157$ and Staphylococcus aureus, were selected for developing this detection method. The detection of pathogenic dsDNA with ZFPs immobilized on magnetic beads has demonstrated high specificity along with multiplexing capability, suggesting a potential for development into a simple and direct point-of-care (POC) testing for pathogenic detection.

\section{Materials and Methods}

\section{Construction, Expression, and Purification of ZFPs}

All ZFPs were constructed, expressed, and purified as described in the previous study [23,25]. Each ZFP was constructed by the modular assembly method using the Barbas set of modules [22]. The vector enables bacterial expression of the proteins as fusions with an $\mathrm{N}$-terminal maltose binding protein (MBP) as a purification tag. Proteins were expressed in E. coli BL21 (Invitrogen) upon induction with $1 \mathrm{mM}$ isopropyl $\beta$-D-1-thiogalactopyranoside (IPTG) at an OD600 of $0.6-0.8$ for $3 \mathrm{~h}$ at $37^{\circ} \mathrm{C}$. Cells were pelleted and resuspended in Zinc Buffer A (ZBA: $100 \mathrm{mM}$ Tris base, $90 \mathrm{mM} \mathrm{KCl}, 1 \mathrm{mM} \mathrm{MgCl}_{2}$ and $100 \mathrm{mM} \mathrm{ZnCl}_{2}$ at $\mathrm{pH}$ 7.5) including $5 \mathrm{mM}$ dithiothreitol (DTT) and $50 \mathrm{mg} / \mathrm{ml} \mathrm{RNase} \mathrm{A.} \mathrm{After} \mathrm{sonication,} \mathrm{proteins} \mathrm{in} \mathrm{cell} \mathrm{lysate} \mathrm{were} \mathrm{applied} \mathrm{to} \mathrm{an} \mathrm{amylose} \mathrm{resin} \mathrm{column} \mathrm{pre-}$ equilibrated with ZBA containing $5 \mathrm{mM}$ DTT, washed with ZBA containing $2 \mathrm{M} \mathrm{NaCl}$ and ZBA containing $1 \mathrm{mM}$ tris(2-carboxyethyl) phosphine (TCEP), and eluted in ZBA containing $10 \mathrm{mM}$ maltose and $1 \mathrm{mM}$ TCEP. Concentration and purity were assessed by Coomassie-stained polyacrylamide gel electrophoresis with sodium dodecyl sulfate (SDS-PAGE) using bovine serum albumin (NEB) standards. A purified protein was stored in ZBA containing $1 \mathrm{mM}$ TCEP at $4^{\circ} \mathrm{C}$ until use.

\section{ZFP Conjugation on Magnetic Beads}

The protein storage buffer was exchanged to ZHEPES buffer ( $\mathrm{pH} 7.5$ ) containing $20 \mathrm{mM}$ 4-(2-hydroxyethyl)-1-

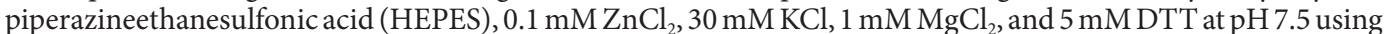
$10-\mathrm{kDa}$ Amicon filter unit (MilliporeSigma, Burlington, MA) by centrifugation at $4,000 \times g$ for $1 \mathrm{~h}$ at $4^{\circ} \mathrm{C}$. The ZFP concentration was re-evaluated using a Nanodrop (ThermoFisher, Waltham, MA). The concentrated ZFP was conjugated on Dynabeads M-280 Tosylactivated (ThermoFisher, USA) according to the manufacturer's protocol. The magnetic beads are polystyrene beads coated with a polyurethane layer. $1 \mathrm{mg}$ of the magnetic beads was washed with $35 \mathrm{ml}$ buffer A (0.1 M borate buffer $\mathrm{pH} 9.5)$ twice and then incubated $12-16 \mathrm{~h}$ with a mixture of $20 \mathrm{mg}$ of ZFP, $30 \mathrm{ml}$ of buffer $\mathrm{A}$, and $20 \mathrm{ml}$ of buffer C ( $3 \mathrm{M}$ ammonium sulfate in Buffer B containing $0.1 \mathrm{M}$ sodium phosphate buffer with $0.1 \mathrm{mM} \mathrm{ZnCl}_{2}, \mathrm{pH} 7.4$ ) at $37^{\circ} \mathrm{C}$ with shaking at $250 \mathrm{rpm}$. After overnight incubation, the beads were incubated with buffer D (PBS pH 7.4 with $0.5 \%$ (w/v) BSA, $5 \mathrm{mM} \mathrm{DTT}$, and $0.1 \mathrm{mM} \mathrm{ZnCl}_{2}$ ) for $1 \mathrm{~h}$ at $37^{\circ} \mathrm{C}$ with shaking at $250 \mathrm{rpm}$ and washed thoroughly using buffer $\mathrm{E}$ (PBS at $\mathrm{pH} 7.4$ with $0.1 \%(\mathrm{w} / \mathrm{v}) \mathrm{BSA}, 5 \mathrm{mM}$ DTT, and $0.1 \mathrm{mM} \mathrm{ZnCl}_{2}$ ) twice. Finally, $48 \mathrm{ml}$ of buffer $\mathrm{E}$ was added and stored at $4^{\circ} \mathrm{C}$ until use.

\section{Multiple Target DNA Detection by ZFPs}

Single-stranded target DNA oligonucleotides were purchased from Integrated DNA Technologies (IDT, USA). Their sequences are provided in Table 1. We purchased dye-labeled target DNA oligonucleotides for ZFP Stx2-268 with Alexa 488 (excitation at $490 \mathrm{~nm}$, emission at $520 \mathrm{~nm}$ ) and ZFP SEB-435 with Texas red (excitation at $596 \mathrm{~nm}$, emission at $620 \mathrm{~nm}$ ), respectively. Target dsDNA oligonucleotides were prepared by heating at $95^{\circ} \mathrm{C}$ for $10 \mathrm{~min}$ and then slowly cooling down to ambient temperature to form hairpins containing a four-thymidine loop as described in the previous study $[23,25] .5 \mu \mathrm{l}$ of target dsDNA was applied to the ZFP-conjugated beads for binding. After a 20 min incubation at ambient temperature with gentle shaking, unbound DNA was washed away twice by magnetically isolating the bead-bound complex as illustrated in Fig. 1. The first wash buffer contains $50 \mathrm{mM} \mathrm{KCl}$ in ZBA buffer, and the second wash buffer contains $0.05 \%$ Tween-20 in ZBA buffer. The fluorescence intensity of the bead-bound complex was measured using a fluorescence microscope (Axiopan 2ie, Carl Zeiss, Germany). The intensity of a single bead on the fluorescence image was quantified using the NIH Image J software and data was statistically analyzed with the $t$-test.

Table 1. Sequences of the target DNA oligonucleotides.

\begin{tabular}{cc}
\hline Target & \multicolumn{1}{c}{ Sequence } \\
\hline Stx2-268 & 5'-GAC GGC TTG ATG TCT ATC AGG CGC GTT TTG ACC ATC TTC GGG TTTT CCC GAA GAT GGT \\
& CAA AAC GCG CCT GAT AGA CAT CAA GCC GTC-3' \\
SEB-435 & 5'-GAC GGT GTG ACC GAG CAT GAT GGA AAT CAA ATA GAT AAA CCC TTTT GGG TTT ACT TAT \\
& TTG ATT TCC ATC ATG CTC GGT CAC ACC GTC-3' \\
\hline
\end{tabular}


A

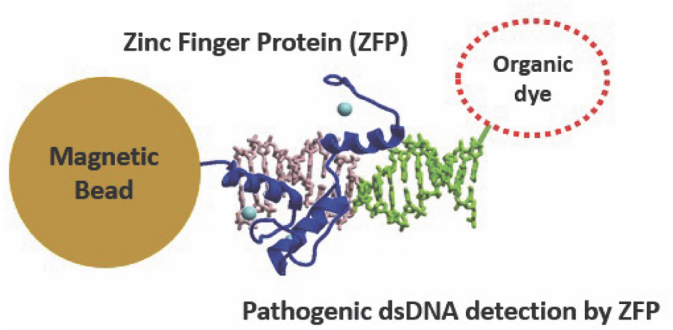

B

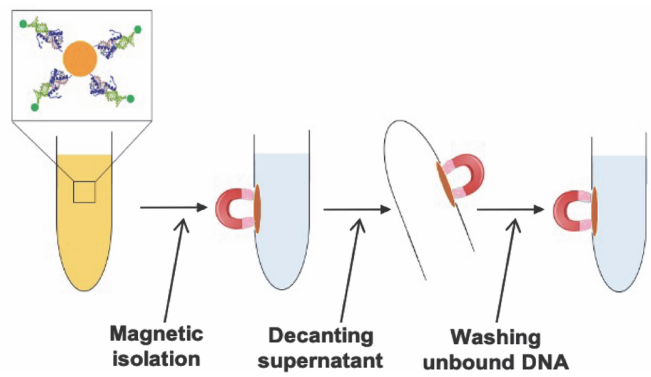

Fig. 1. Schematic diagram of (A) the bead-bound complex of ZFP and fluorophore-labeled dsDNA on the magnetic beads and (B) magnetic isolation of the bead-bound complex before fluorescence measurement.

\section{Results and Discussion}

In this study, we employed paramagnetic beads with two ZFP probes, Stx2-268 and SEB-435, to develop a simple and rapid method for detection of pathogens. Magnetic beads could be isolated rapidly and provide a larger platform area to volume ratio, allowing for more ZFP molecule binding compared to the 2-dimentional surface. The magnetic beads used in this study are superparamagnetic and their size is uniformly $2.8 \mu \mathrm{m}$ in diameter. The magnetic beads bind to ZFPs covalently through primary amino or sulfhydryl groups. After ZFPs conjugated on the beads bind target DNA form the protein-DNA bound complex, unbound molecules are washed out by magnetically isolating the bead-bound complex as illustrated in Fig. 1.

\section{Target DNA Detection on a Magnetic Bead-Based Platform}

Engineered ZFPs were highly expressed in E. coli and purified to approximately $90 \%$ purity. Engineered ZFP Stx2-268 binds to $18 \mathrm{bp}$ of DNA sequence in the stx 2 gene encoding for the shiga toxin produced by E. coli O157. The ZFP SEB-435 engineered to recognize the seb gene encoding for the staphylococcal enterotoxin B in S. aureus was examined along with ZFP Stx2-268 in this study. To validate the magnetic bead-based detection platform, the ZFP assay was performed at various concentrations of target DNA oligonucleotides, ranging from $4 \mathrm{nM}$ to $2.5 \mu \mathrm{M}$. The dsDNA of each target was applied to ZFPs immobilized on the magnetic beads. As the DNA concentration increases, the fluorescence signal obtained from individual beads using a fluorescence microscope increases, as shown in Fig. 2. Green fluorescent Alexa 488-labeled target DNA from the stx2 gene was detected by ZFP Stx2-268 as shown in Fig. 2 (A, B). The fluorescence intensity of individual particles was obtained from the average of three independent experiments where data were collected ranging from 70 to 200 particles ( $1^{\text {st }}$ run), 60 to 200 particles $\left(2^{\text {nd }}\right.$ run), and 60 to 300 particles ( $3^{\text {rd }}$ run). The limit of detection was determined to be $4 \mathrm{nM}$ for ZFP Stx2-268 ( $p<$ 0.05 ) which is equivalent to $60 \mathrm{fmol}$. Texas red-labeled target DNA from the seb gene was detected by ZFP SEB-435 as shown in Fig. 2 (C, D). The fluorescence intensity of individual particles was obtained from the average of three independent experiments where data were collected ranging from 150 to 200 particles ( $1^{\text {st }}$ run), 100 to 200 particles ( $2^{\text {nd }}$ run), and 100 to 300 particles ( $3^{\text {rd }}$ run). The result of the statistical analysis indicates that the ZFP SEB-435 was not significantly sensitive enough to detect $\leq 4 \mathrm{nM}$ of target DNA. We found that the limit of detection was affected by the autofluorescence originating from the magnetic bead itself [32] as shown in the image i (No DNA) of Fig. 2 (B, D). The autofluorescence of the beads can increase background signal and reduces the assay sensitivity [32].

A potential improvement to this system could be the use of magnetic beads with minimal autofluorescence such as silicone magnetic beads [32], which could lead to enhanced sensitivity of the fluorescence-based assay. Also, further optimization of our system could improve the limit of detection by decreasing the amount of magnetic beads and increasing the amount of ZFP molecules. Although this magnetic bead-based platform is currently not as sensitive as the established leading nucleic acid-based methods such as PCR, our bead and ZFP-based detection system does not require additional steps involved in DNA denaturation and subsequent hybridization with carefully designed primers or probes due to the direct detection of dsDNA with customized ZFPs. In addition, our system does not require careful control of temperature nor expensive reagents needed for PCR. It should be noted that our system provides clear visual detection within a short assay time compared to an assay time of 2-3 h required for PCR. Our detection system lies in the utilization of flow based micro-scale assay along with a paramagnetic solid phase for immobilization and a magnet, which allows localized and convenient detection, small waste generation and reagent consumption, and a short overall assay time. Therefore, our system can be integrated into a microfluidic chip for developing a POC device. The beads coupled with a ZFP probe would be flown into a microfluidic chip and packed by a magnet placed underneath the chip. The fluorophore-labeled target DNA would then be pumped into the chip, thereby analyzing fluorescence signal of the protein-DNA bound complex. This application of ZFP array into a microfluidic module could lead to improvement in the sensitivity through pre-concentration of the sample.

The DNA binding affinities $\left(\mathrm{k}_{\mathrm{D}}\right)$ of ZFP Stx2-268 and ZFP SEB-435 are 1.98 and $0.3 \mathrm{nM}$, respectively as shown in Table $2[23,25]$. While ZFPs with a stronger binding affinity may retain target DNA for a longer time, our 


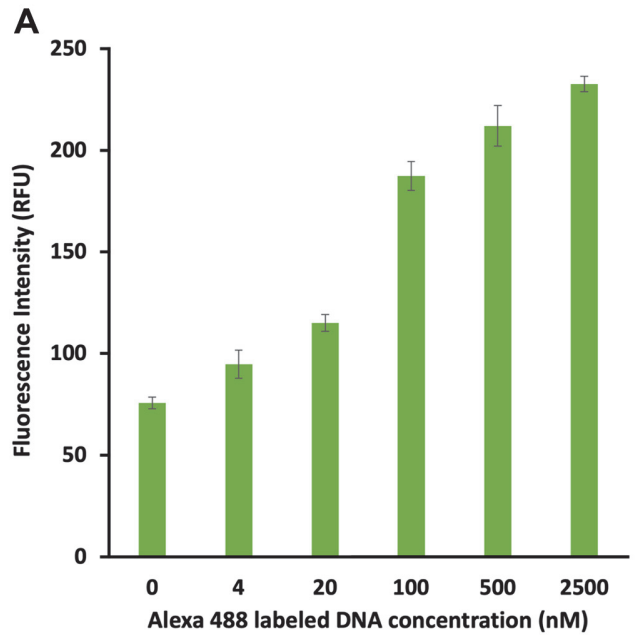

B
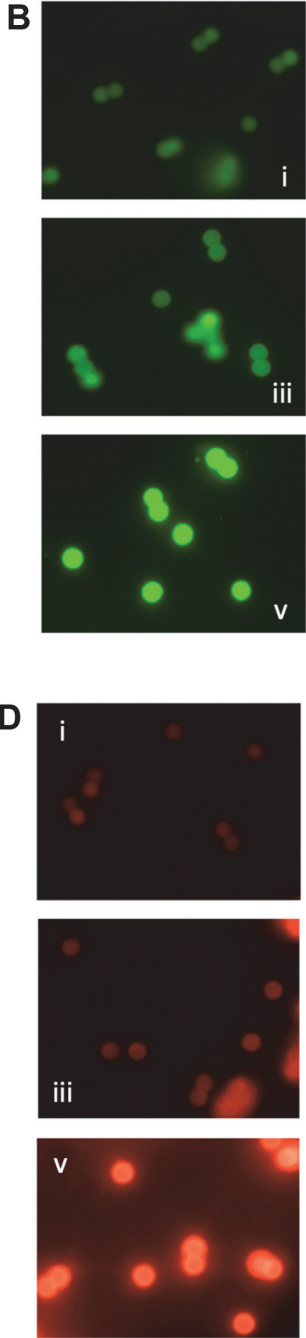
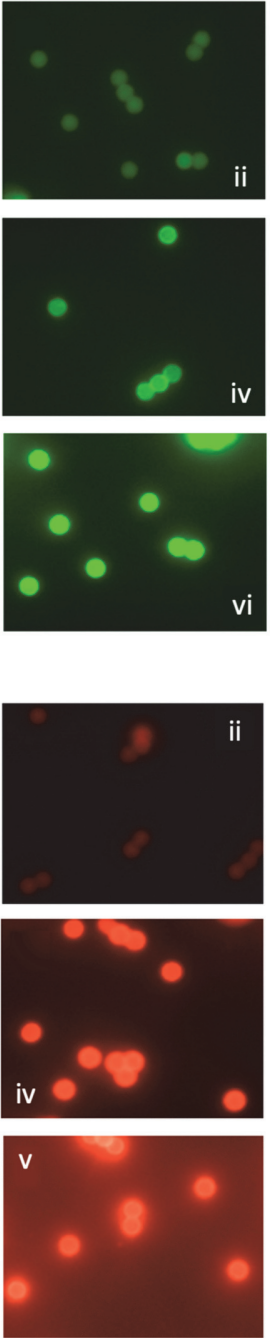

Fig. 2. Target DNA detection with engineered ZFPs on a magnetic bead-based platform. (A,C) The bar graph representing the fluorescence intensity of individual particles obtained from $(\mathbf{B}, \mathbf{D})$ images taken by fluorescence microscopy (i: $0 \mathrm{nM}$, ii: $4 \mathrm{nM}$, iii: $20 \mathrm{nM}$, iv: $100 \mathrm{nM}$, v: $500 \mathrm{nM}$, and vi: $2500 \mathrm{nM} \mathrm{DNA}$ ). (A, B) Alexa 488-labeled target DNA was detected by ZFP Stx2-268. (C, D) Texas red-labeled target DNA was detected by ZFP SEB-435.

Table 2. Zinc finger recognition modules with their corresponding 3 bp DNA subsites, and the $k_{\mathrm{D}}$ values of zinc finger proteins.

\begin{tabular}{lclllllll}
\hline \multicolumn{1}{c}{ ZFP } & Position & Finger 6 & Finger 5 & Finger 4 & Finger 3 & Finger 2 & Finger 1 & $k_{\mathrm{D}}(\mathrm{nM})$ \\
\hline Target site & \multirow{2}{*}{268} & GAA & GAT & GGT & CAA & AAC & GCG & 1.98 \\
Stx2-268 & & RSDDLVR & DSGNLRV & QSGNLTE & TSGHLVR & TSGNLVR & QSSNLVR & \\
Target site & \multirow{2}{*}{435} & GGA & AAT & CAA & ATA & GAT & AAA & 0.3 \\
SEB-435 & & QRANLRA & TSGNLVR & QKSSLIA & QSGNLTE & TTGNLTV & QRAHLER &
\end{tabular}

observation may not allow for a clear correlation between the binding affinity of ZFPs and their detection characteristics.

\section{Specificity}

The DNA binding specificity was examined to investigate if engineered ZFPs are able to distinguish its own target DNA from non-target DNA. Mixtures containing $500 \mathrm{nM}$ of both target DNAs were applied to each ZFP immobilized on the magnetic beads. As shown in Fig. 3, fluorescence signal was only observed when incubated with their respective ZFP because both ZFPs bound to only its cognate DNA in the presence of non-target DNA. Non-target DNA was washed away as shown in the image ii' of Fig. 3B and the image ii of Fig. 3C since the signal intensity of non-target DNA is the same as the baseline autofluorescence of the beads. Thus, our system demonstrated high specificity. 


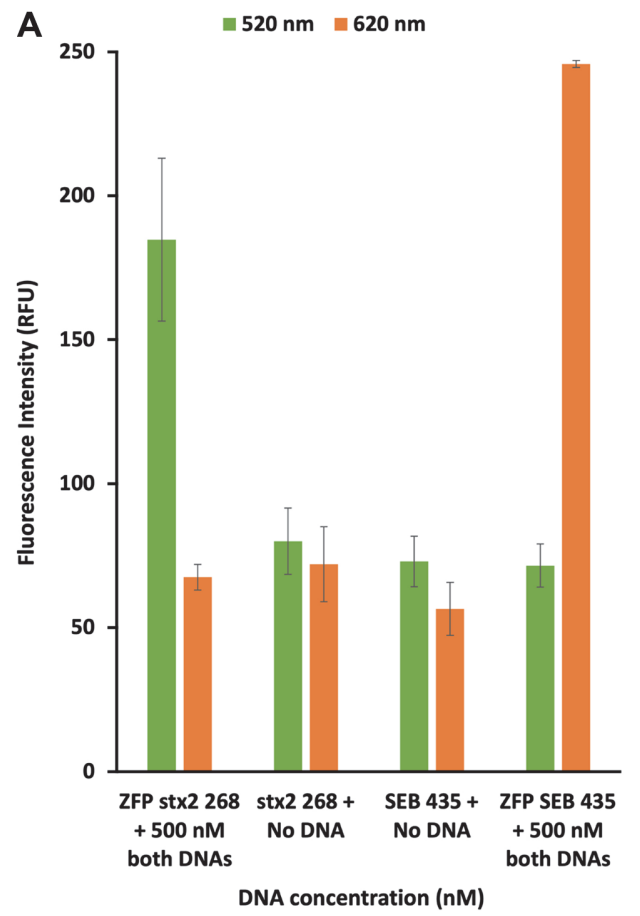

B
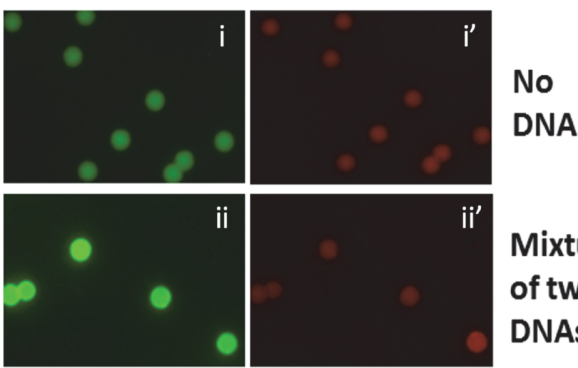

Mixture

of two

DNAs

stx2-268 conjugated beads
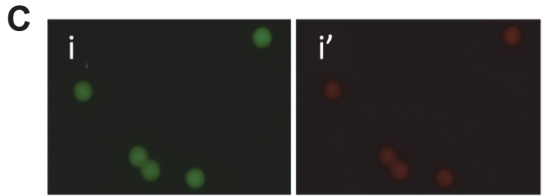

No

DNA
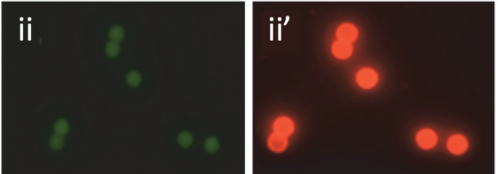

Mixture

of two

DNAs

seb 435 conjugated beads

Fig. 3. Specificity of engineered ZFPs (Stx2-268 and SEB-435). A mixture of two target DNAs was applied to both ZFPs. (A) The bar graph representing the fluorescence intensity of individual particles obtained from (B, C) images taken by fluorescence microscopy.

\section{Multiplexed Detection}

The capability of multiplexed detection of our system was investigated as shown in Fig. 4. Mixtures of both DNAs in various concentrations from 50 to $500 \mathrm{nM}$ were applied to both ZFPs immobilized on magnetic beads. The fluorescence intensity of individual particles was obtained from the average of three independent experiments where data were collected ranging from 200 to 300 particles ( $1^{\text {st }}$ run), 150 to 200 particles ( $2^{\text {nd }}$ run),

A

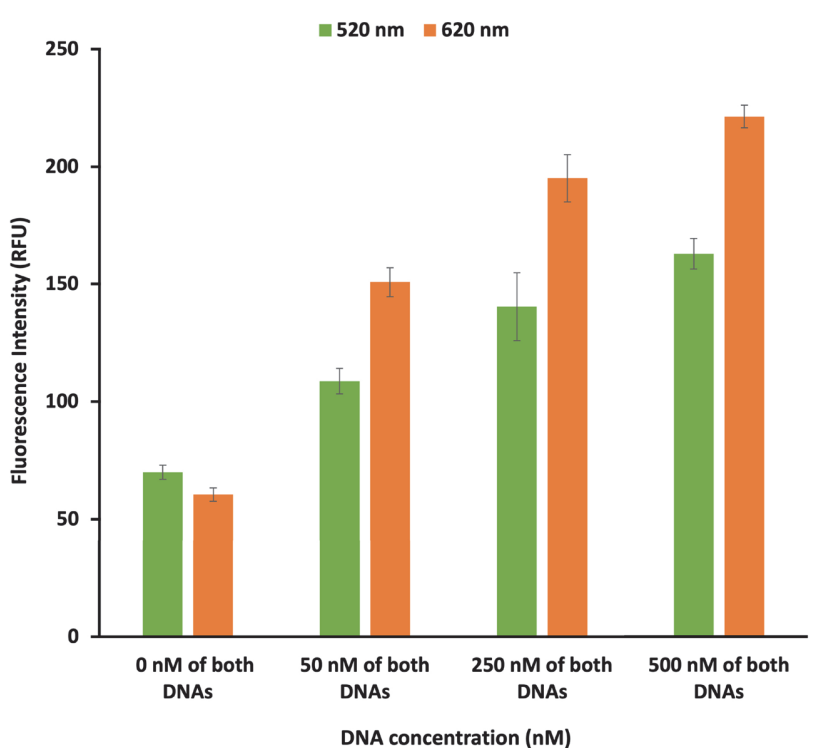

B
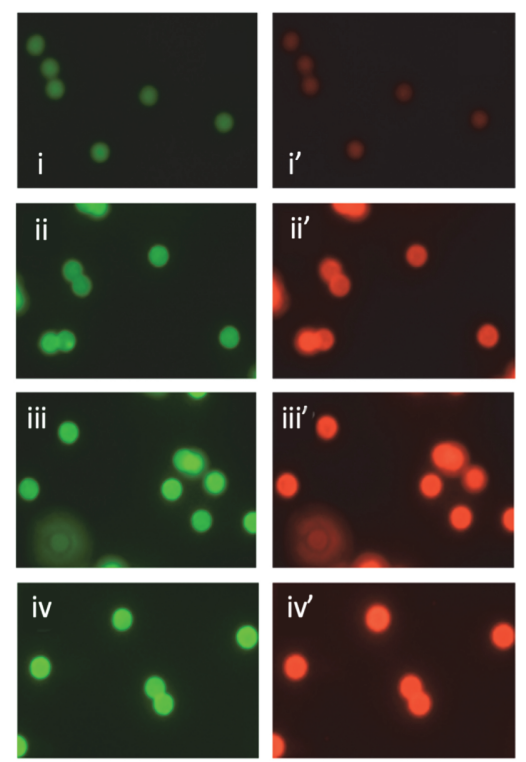

Fig. 4. Multiplexed detection of target dsDNA by engineered ZFPs (Stx2-268 and SEB-435). (A) The bar graph representing the fluorescence intensity of individual particles obtained from (B) images taken by fluorescence microscopy (i and i': $0 \mathrm{nM}$, ii and ii': $50 \mathrm{nM}$, iii and iii': $250 \mathrm{nM}$, iv and iv': $500 \mathrm{nM}$ of both DNA mixture applied to both ZFPs). 
and 150 to 300 particles ( $3^{\text {rd }}$ run). The fluorescence signals from two different target DNAs exhibit different intensities simultaneously, indicating that each ZFP recognized its cognate DNA at the same time in the presence of two different target DNAs. The DNA-dose dependent signal was observed for both ZFPs. Our results demonstrated that the bead-conjugated ZFP-based method can detect multiple targets simultaneously, suggesting its potential for development into a simple and reliable method for multiplexed detection of pathogens.

\section{Conclusions}

We have demonstrated a simple, rapid, and direct method for multiplexed detection of pathogens by isolating magnetic beads conjugated with ZFPs bound to pathogen-specific dsDNA. Our system allows for directly detecting pathogen-specific dsDNA, obviating the need for DNA denaturation and hybridization, and for efficiently isolating the protein-DNA bound complex through magnetic beads. The high specificity of our system has been demonstrated by the recognition of their own target DNA by ZFPs in the presence of non-target DNA. This bead- and ZFP-based detection system also demonstrated a multiplexing capability by detecting multiple target DNAs simultaneously. In addition, our bead-based assay provides clear visual detection after a $20 \mathrm{~min}$ incubation, which is faster than a $2-3 \mathrm{~h}$ process of PCR. Future studies will be carried out for further optimization to decrease the background noise and increase the ZFP concentration, leading to enhanced sensitivity. Since we have demonstrated in this study a proof-of concept for application of our system for detecting pathogenic DNA, cell lysates would be utilized for practical application of our future study. In our recently published report [33], engineered ZFPs were able to detect specific genes when using prepurified genomic DNAs of E. coli O157 and S. aureus as in real-world settings. Thus, we expect that our future study with cell lysates could potentially lead to promising results. In parallel, we will focus on integrating our system into a microfluidic chip for the purpose of developing POC application.

\section{Acknowledgments}

This research was supported by the Kentucky Biomedical Research Infrastructure Network (KBRIN)Institutional Development Award (IDeA) from the National Institute of General Medical Sciences of the National Institutes of Health under grant number 2P20GM10343614, and National Science Foundation (NSF)-International Research Experiences for Students (IRES) Award under grant number IIA-1358222.

\section{Conflict of Interest}

The authors have no financial conflict of interest to declare.

\section{References}

1. Chinen AB, Guan CM, Ferrer JR, Barnaby SN, Merkel TJ, Mirkin CA. 2015. Nanoparticle probes for the detection of cancer biomarkers, cells, and tissues by fluorescence. Chem. Rev. 115: 10530-10574.

2. Mirasoli M, Guardigli M, Michelini E, Roda A. 2014. Recent advancements in chemical luminescence-based lab-on-chip and microfluidic platforms for bioanalysis. J. Pharm. Biomed. Anal. 87: 36-52.

3. Shim J, Nikolov A, Wasan D. 2017. Escherichia coli removal from model substrates: Underlying mechanism based on nanofluid structural forces. J. Colloid. Interface Sci. 498: 112-122.

4. Shim J, Stewart DS, Nikolov AD, Wasan DT, Wang R, Yan R, et al. 2017. Differential MS2 interaction with food contact surfaces determined by atomic force microscopy and virus recovery. Appl. Environ. Microbiol. 83: e01881-17.

5. Zhao T, Zhao P, Doyle MP. 2009. Inactivation of Salmonella and Escherichia coli O157:H7 on lettuce and poultry skin by combinations of levulinic acid and sodium dodecyl sulfate. J. Food Prot. 72: 928-936.

6. Shieh YC, Tortorello ML, Fleischman GJ, Li D, Schaffner DW. 2014. Tracking and modeling norovirus transmission during mechanical slicing of globe tomatoes. Int. J. Food Microbiol. 180: 13-18.

7. Cleven BE, Palka-Santini M, Gielen J, Meembor S, Kronke M, Krut O. 2006. Identification and characterization of bacterial pathogens causing bloodstream infections by DNA microarray. J. Clin. Microbiol. 44: 2389-2397.

8. Palka-Santini M, Cleven BE, Eichinger L, Kronke M, Krut O. 2009. Large scale multiplex PCR improves pathogen detection by DNA microarrays. BMC Microbiol. 9: 1.

9. Wang C, Wu B, Amer S, Luo J, Zhang H, Guo Y, et al. 2010. Phylogenetic analysis and molecular characteristics of seven variant Chinese field isolates of PRRSV. BMC Microbiol. 10: 146.

10. Wang D, Coscoy L, Zylberberg M, Avila PC, Boushey HA, Ganem D, et al. 2002. Microarray-based detection and genotyping of viral pathogens. Proc. Natl. Acad. Sci. USA 99: 15687-15692.

11. Warsen AE, Krug MJ, LaFrentz S, Stanek DR, Loge FJ, Call DR. 2004. Simultaneous discrimination between 15 fish pathogens by using 16S ribosomal DNA PCR and DNA microarrays. Appl. Environ. Microbiol. 70: 4216-4221.

12. Peplies J, Lau SCK, Pernthaler J, Amann R, Glockner FO. 2004. Application and validation of DNA microarrays for the 16S rRNAbased analysis of marine bacterioplankton. Environ. Microbiol. 6: 638-645.

13. Wu LY, Thompson DK, Li GS, Hurt RA, Tiedje JM, Zhou JZ. 2001. Development and evaluation of functional gene arrays for detection of selected genes in the environment. Appl. Environ. Microbiol. 67: 5780-5790.

14. Beerli RR, Barbas CF. 2002. Engineering polydactyl zinc-finger transcription factors. Nat. Biotechnol. 20: 135-141.

15. Wolfe SA, Nekludova L, Pabo CO. 2000. DNA recognition by Cys(2)His(2) zinc finger proteins. Ann. Rev. Biophy. Biomol. Struct. 29: 183-212.

16. Pavletich NP, Pabo CO. 1991. Zinc finger DNA recognition - Crystal-structure of a Zif268-DNA complex at 2.1-A. Science 252: 809-817.

17. Kim MS, Kini AG. 2017. Engineering and application of zinc finger proteins and TALEs for biomedical research. Mol. Cells 40: 533-541.

18. Dreier B, Beerli RR, Segal DJ, Flippin JD, Barbas CF. 2001. Development of zinc finger domains for recognition of the 5 '-ANN-3 ' family of DNA sequences and their use in the construction of artificial transcription factors. J. Biol. Chem. 276: 29466-29478.

19. Dreier B, Segal DJ, Barbas CF. 2000. Insights into the molecular recognition of the 5 '-GNN-3 ' family of DNA sequences by zinc finger domains. J. Mol. Biol. 303: 489-502.

20. Liu Q, Segal DJ, Ghiara JB, Barbas CF. 1997. Design of polydactyl zinc-finger proteins for unique addressing within complex genomes. Proc. Natl. Acad. Sci. USA 94: 5525-5530. 
21. Segal DJ, Dreier B, Beerli RR, Barbas CF. 1999. Toward controlling gene expression at will: Selection and design of zinc finger domains recognizing each of the 5 '-GNN-3 ' DNA target sequences. Proc. Natl. Acad. Sci. USA 96: 2758-2763.

22. Bhakta MS, Segal DJ. 2010. The generation of zinc finger proteins by modular assembly. Methods Mol. Biol. 649: 3-30.

23. Ha DT, Ghosh S, Ahn CH, Segal DJ, Kim MS. 2018. Pathogen-specific DNA sensing with engineered zinc finger proteins immobilized on a polymer chip. Analyst 143: 4009-4016.

24. Kim MS, Stybayeva G, Lee JY, Revzin A, Segal DJ. 2011. A zinc finger protein array for the visual detection of specific DNA sequences for diagnostic applications. Nucleic Acids Res. 39: e29.

25. Kim MS, Kim J. 2016. Multiplexed detection of pathogen-specific DNA using engineered zinc finger proteins without target amplification. Anal. Methods 8: 6696-6700.

26. Fang CS, Kim KS, Yu B, Jon S, Kim MS, Yang H. 2017. Ultrasensitive electrochemical detection of miRNA-21 using a zinc finger protein specific to DNA-RNA hybrids. Anal. Chem. 89: 2024-2031.

27. Porter JR, Stains CI, Segal DJ, Ghosh I. 2007. Split beta-lactamase sensor for the sequence-specific detection of DNA methylation. Anal. Chem. 79: 6702-6708.

28. Kim C, Hoffmann G, Searson PC. 2017. Integrated magnetic bead-quantum dot immunoassay for malaria detection. ACS Sens. 2: $766-772$

29. Lee H, Shin TH, Cheon J, Weissleder R. 2015. Recent developments in magnetic diagnostic systems. Chem. Rev. 115: 10690-10724.

30. Shim WB, Song JE, Mun H, Chung DH, Kim MG. 2014. Rapid colorimetric detection of Salmonella typhimurium using a selective filtration technique combined with antibody-magnetic nanoparticle nanocomposites. Anal. Bioanal. Chem. 406: 859-866.

31. Hayes MA, Polson NA, Phayre AN, Garcia AA. 2001. Flow-based microimmunoassay. Anal. Chem. 73: 5896-5902.

32. Evans BA, Ronecker JC, Han DT, Glass DR, Train TL, Deatsch AE. 2016. High-permeability functionalized silicone magnetic microspheres with low autofluorescence for biomedical applications. Mater. Sci. Eng. C Mater. Biol. Appl. 62: 860-869.

33. Ha DT, Nguyen VT, Kim MS. 2021. Graphene oxide-based simple and rapid detection of antibiotic resistance gene via quantum dotlabeled zinc finger proteins. Anal. Chem. 3: 8459-8466. 